\title{
Adult subventricular zone neural stem cells as a potential source of dopaminergic replacement neurons
}

\author{
John W. Cave ${ }^{1,2 *}$, Meng Wang ${ }^{1,2}$ and Harriet Baker ${ }^{1,2}$ \\ Brain and Mind Research Institute, Weill Cornell Medical College, New York, NY, USA \\ ${ }^{2}$ Burke Medical Research Institute, White Plains, NY, USA
}

\section{Edited by:}

Antoine De Chevigny,

Developmental Biology Institute of

Marseille Luminy, France

Reviewed by:

Luca Bonfanti, University of Turin,

Italy

Umberto Di Porzio, Institute of

Genetics and Biophysics "Adriano

Buzzati Traverso," Italy

*Correspondence:

John W. Cave, Weill Cornell Medical College, Burke Medical Research

Institute, 785 Mamaroneck Avenue,

White Plains, NY, 10605, USA

e-mail: joc2042@med.cornell.edu
Clinical trials engrafting human fetal ventral mesencephalic tissue have demonstrated, in principle, that cell replacement therapy provides substantial long-lasting improvement of motor impairments generated by Parkinson's Disease (PD). The use of fetal tissue is not practical for widespread clinical implementation of this therapy, but stem cells are a promising alternative source for obtaining replacement cells. The ideal stem cell source has yet to be established and, in this review, we discuss the potential of neural stem cells in the adult subventricular zone (SVZ) as an autologous source of replacement cells. We identify three key challenges for further developing this potential source of replacement cells: (1) improving survival of transplanted cells, (2) suppressing glial progenitor proliferation and survival, and (3) developing methods to efficiently produce dopaminergic neurons. Subventricular neural stem cells naturally produce a dopaminergic interneuron phenotype that has an apparent lack of vulnerability to PD-mediated degeneration. We also discuss whether olfactory bulb dopaminergic neurons derived from adult SVZ neural stem cells are a suitable source for cell replacement strategies.

Keywords: subventricular zone, olfactory bulb, neural stem cells, adult neurogenesis, dopaminergic, cell replacement therapy

\section{INTRODUCTION}

Parkinson's Disease (PD) is one of the most prevalent neurodegenerative disorders and afflicts $\sim 1 \%$ of the population over 60 years of age in industrialized nations (Nussbaum and Ellis, 2003). PD affects several regions of the nervous system that result in many clinical symptoms (Braak et al., 2004; Poewe, 2008). The most characteristic symptoms, however, are motor system impairments that include tremor, rigidity, and bradykinesia. The pathology underlying these motor symptoms is a progressive degeneration of dopaminergic neurons in the substantia nigra pars compacta. These dopamine neurons modulate control of motor function through axonal projections to the putamen and caudate divisions of the striatum. Standard clinical care is focused on the functional preservation of this nigrostriatal circuit. Pharmacological approaches with L-DOPA and dopamine receptor agonists can ameliorate most motor symptoms, particularly in the early stages after a clinical diagnosis. As the disease progresses, however, medication regimens become less effective and surgical strategies, such as deep brain stimulation, can provide symptomatic relief. Both the pharmacological and surgical interventions ultimately fail though because they do not stop the progressive degeneration of midbrain dopaminergic neurons.

Cell replacement strategies are a fundamentally different type of therapy because they introduce new dopaminergic neurons that can restore striatal dopamine levels. Clinical trials engrafting human fetal ventral mesencephalic tissue containing dopaminergic neuronal progenitors into the striatum demonstrated, in principle, that this approach can provide substantial long-lasting improvement of motor symptoms
(Widner et al., 1992; Defer et al., 1996; Freed et al., 2001; Mendez et al., 2002; Olanow et al., 2003). Some patients in these trials improved post-operatively to a point where L-DOPA therapy was no longer required, but others experienced negligible long-term improvement and, in some cases, severe graft-induced dyskinesias developed and required additional surgical intervention.

\section{IDEAL FEATURES OF REPLACEMENT CELL SOURCES}

Analyses of the clinical trials identified several features of replacement cells that are essential for favorable functional outcomes (Wijeyekoon and Barker, 2009; Lindvall and Bjorklund, 2011). These features include establishing replacement cell sources that are autologous, or at the least allogenic, since immunosuppression appears to improve engrafted cell survival and clinical outcomes (Olanow et al., 2003). The survival rate of transplanted cells is an important practical issue and sources that provide replacement cells with higher survival rates reduce the total amount of donor material required. Significant clinical benefit is estimated to require the survival of at least 100,000 engrafted dopaminergic neurons per putamen (Hagell and Brundin, 2001). Clinical improvement is also more likely achieved with sources that can be used as dissociated cell suspensions. Unlike solid tissue grafts, cell suspensions can readily disperse and evenly innervate target areas. Studies of engraftments in both humans and rodents indicate the uneven and patchy reinnervation of the putamen promotes the development of adverse dyskinesia side effects (Ma et al., 2002; Carlsson et al., 2006; Maries et al., 2006). The risk of dyskinesias is also reduced with replacement cell sources that can be prepared by standardized protocols that minimize 
the presence of undesired phenotypes. The presence of serotonergic progenitors in fetal mesencephalic tissue, for example, is believed to contribute to the incidence of transplant-related dyskinesias (Politis et al., 2012). Consistent with this possibility, serotonergic neurons transplanted into the striatum of rodent PD models exacerbate dyskinesias induced by L-DOPA (Carlsson et al., 2007).

\section{EMBRYONIC AND INDUCED PLURIPOTENT STEM CELL SOURCES}

The ideal source of replacement cells for PD has not been established (reviewed in Meyer et al., 2010). Fetal mesencephalic tissue is not practical because of the difficulty in standardizing donor tissue and ethical concerns of how to generate the necessary amounts of material required for widespread clinical use. Stem cells, however, are a promising source of replacement cells that meet the requirements for creating favorable clinical outcomes (discussed above). Several studies have demonstrated the feasibility of stem cell based therapies using embryonic stem cells (Bjorklund et al., 2002; Kim et al., 2002; Takagi et al., 2005; Roy et al., 2006; Rodriguez-Gomez et al., 2007; Cho et al., 2008; Sanchez-Pernaute et al., 2008; Friling et al., 2009). These studies used a variety of differentiation protocols, but they all showed that transplants of embryonic stem cell-derived dopaminergic neurons into either rodent or primate PD model systems both survive and integrate into the host circuitry to provide significant functional recovery. Embryonic stem cells face several important challenges, however, before they can be considered for human clinical trials. These challenges include developing higher efficiency protocols for dopaminergic neuron production, improving survival of engrafted cells, and methods to completely remove contaminating cell types responsible for tumor or teratoma formation observed in animal trials.

Induced pluripotent stem cells are another potential source of replacement cells. Their broad differentiation potential resembles embryonic stem cells, but the ability to derive these cells from adult tissue avoids the moral and ethical issues of using embryonic stem cell lines. Furthermore, induced pluripotent stem cells are a potential autologous source of replacement cells since they can be generated from a patient's own cells. Recent reports indicate that dopaminergic neurons derived from induced pluripotent stem cells can survive and provide functional improvement in rodent PD model systems (Wernig et al., 2008; Hargus et al., 2010; Swistowski et al., 2010; Rhee et al., 2011; Chang et al., 2012; Sundberg et al., 2013). Advancing induced pluripotent stem cells to a clinical setting faces many of same challenges confronting the use of embyronic stem cells, including improvement in the dopaminergic neuron yields and prevention of tumor formation in the recipient.

\section{REPLACEMENT CELLS DERIVED FROM THE ADULT SVZ ADULT NEURAL STEM CELLS}

Neural stem cells are an alternative source of replacement neurons. These cells lack the pluripotent potential of embryonic and induced pluripotent stem cells, but they also do not have the same teratoma or tumor forming potential. Fetal tissue is a rich source of neural stem cells that can generate a wide array of neuronal phenotypes, but as discussed above, the use of fetal tissue is fraught with moral and ethical problems. By contrast, adult neural stem cells do not have these issues, although they typically generate a more limited number of neuronal phenotypes. In the adult mammalian brain, there are two well-established neurogenic niches: the hippocampal subgranular zone and the subventricular zone (SVZ) of the lateral ventricles (Gage et al., 2008; Seki et al., 2011). Neurons generated in both of these regions are able to integrate into pre-existing neural circuitry, which makes them attractive candidates for cell replacement therapy. Progenitors generated in the subgranular zone migrate to the dentate gyrus and become excitatory glutamatergic granule cells. Subgranular zone neural stem cells are located within the interior of the hippocampus, however, and extracting them without damaging the hippocampus is difficult. SVZ neural stem cells almost exclusively produce inhibitory GABAergic inhibitory interneuron progenitors that migrate to the olfactory bulb glomerular and granule cells layers (production of a small number of excitatory neurons has also been reported in Brill et al., 2009). SVZ neural stem cells reside within the walls of the lateral ventricle and, by penetrating non-eloquent parts of the brain in humans, they can be endoscopically harvested, expanded in vitro and differentiated into both neuronal and glial progenitors (Westerlund et al., 2005). Thus, adult SVZ neural stem cells are a potential clinically feasible source of autologous replacement neurons.

\section{TRANSPLANTATION OF ADULT SVZ CELLS INTO THE STRIATUM}

Several studies have homochronously transplanted either SVZ tissue explants or suspensions of either neurospheres or dissociated cells into the adult rodent striatum (Table 1) (Lois and Alvarez-Buylla, 1994; Herrera et al., 1999; Zhang et al., 2003; Meissner et al., 2005; Richardson et al., 2005; Seidenfaden et al., 2006; Chen et al., 2007a,b; Shim et al., 2007; Deleidi et al., 2011). Similar to other sources of donor cells, the survival rates of transplanted SVZ cells were consistently low. Also similar to clinical trials with fetal tissue, migration of transplanted SVZ cells away from the injection site was greater with dispersed SVZ cultures or neurospheres than with engraftments of tissue explants.

An unexpected and consistent finding in the rodent studies with SVZ-derived cells was the meager differentiation and survival of transplanted neurons. Using either cell suspensions or tissue explants as donor material, many of the surviving cells displayed glial phenotypes and very few expressed markers of mature neurons. The poor neuron yields were surprising since the adult SVZ normally produces large numbers of neuronal progenitors (Luskin, 1993; Lois and Alvarez-Buylla, 1994). Analyses of SVZ progenitor cultures expanded in vitro found a large percentage of cells expressed glial marker genes prior to transplantation (Richardson et al., 2005; Chen et al., 2007b), suggesting that in vitro culture conditions may preferentially select for glial precursors. An exception is a study by Zhang and co-workers that reported achieving a high percentage $(\sim 70 \%)$ of neuronal precursors in SVZ cultures prior to transplantation (Zhang et al., 2003). A majority of cells that survived a month after transplantation were found to have a mature a neuronal phenotype and only a few cells expressed the glial marker GFAP. The reasons for higher levels of neuronal generation and survival in this study are unclear. The interactions between adult SVZ neural 


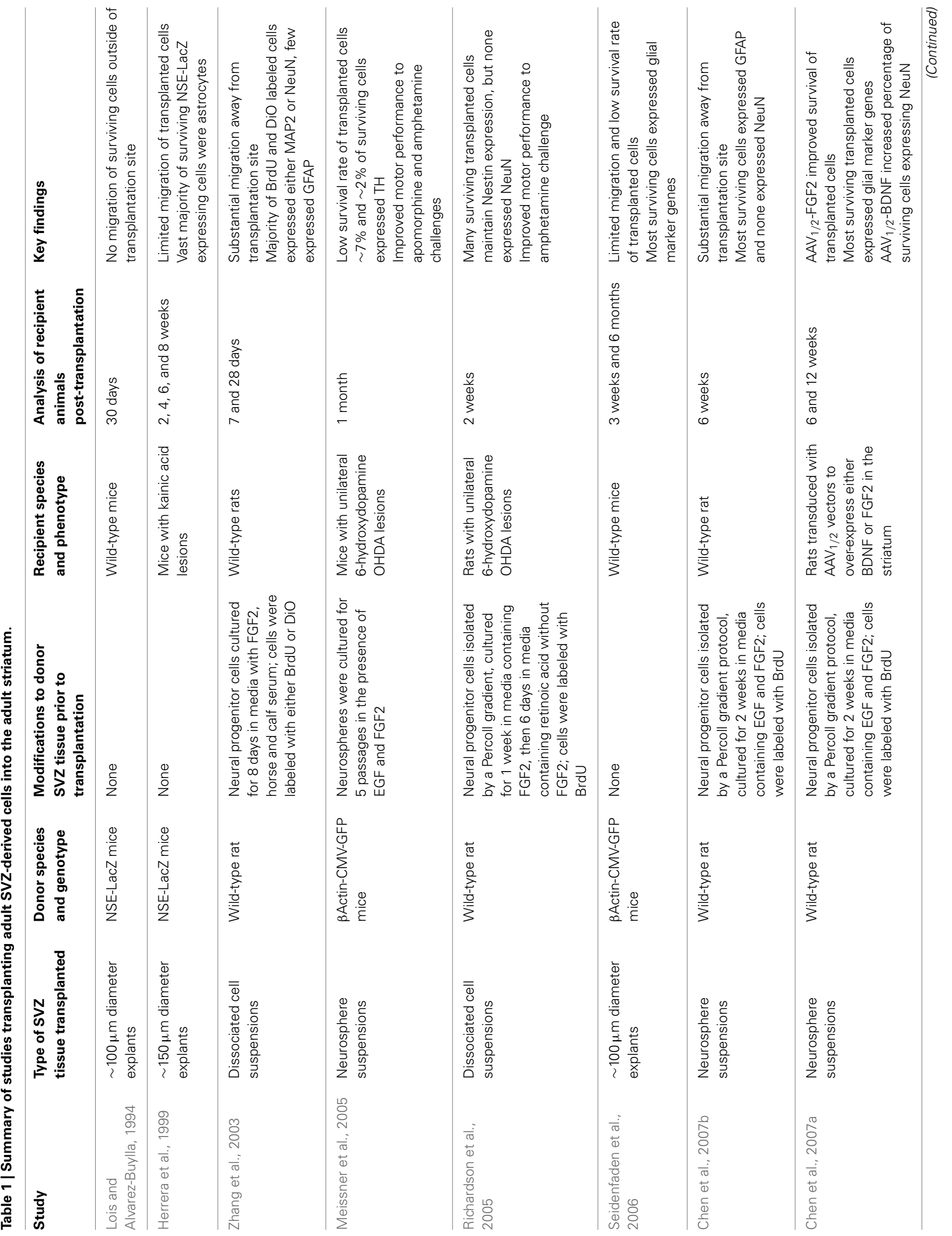




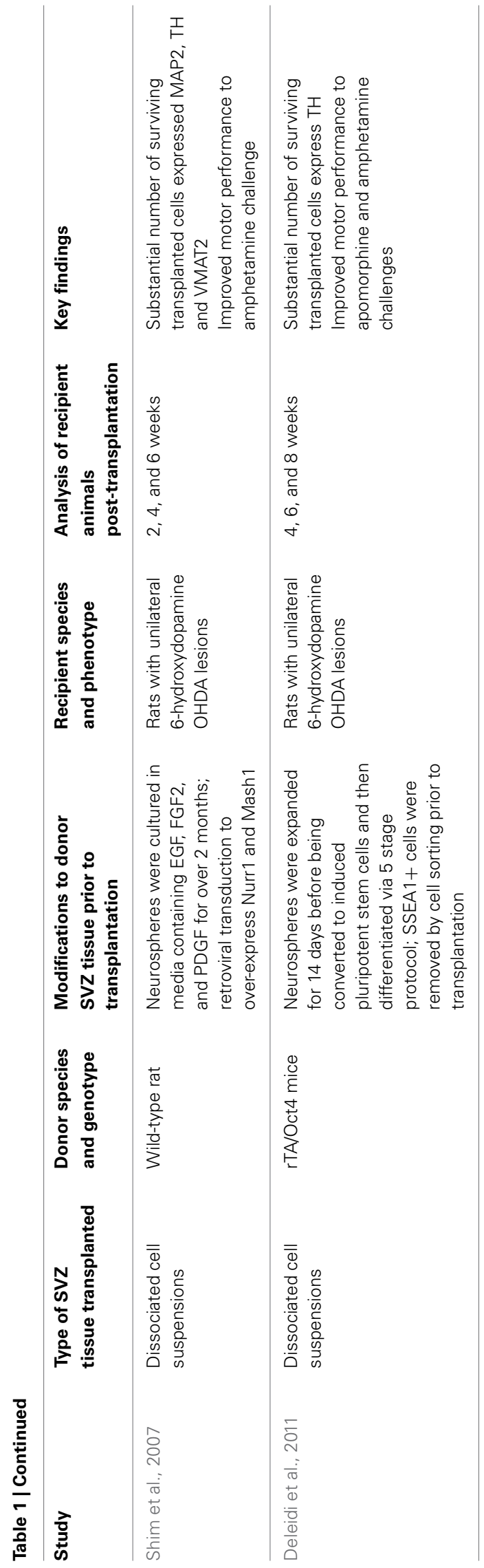

stem cells and their surrounding niche are complex and only just becoming understood (reviewed in Ihrie and Alvarez-Buylla, 2011). Despite their poor neuronal differentiation and survival, transplants of SVZ-derived cells into the host striatum did provide some functional recovery in 6-hydroxydopamine lesioned rodent PD models a month after surgery (Meissner et al., 2005; Richardson et al., 2005). The extent of the improvement was variable, but it does suggest that introduction of glia is not deleterious and may produce some short-term symptomatic improvement.

\section{DOPAMINERGIC DIFFERENTIATION OF SVZ PROGENITORS}

In addition to the poor differentiation and survival of neurons with SVZ-cell transplants, few, if any, of the detectable neurons displayed dopaminergic features. The human clinical trials clearly showed that integration and survival of dopaminergic neurons is essential for sustained long-term functional improvement. Embryonic and induced pluripotent stem cells can be directed toward a dopaminergic cell fate by culturing them with appropriate growth factors and morphogens (Kriks and Studer, 2009; Boyer et al., 2012). Similar protocols can significantly improve neuronal progenitor yields in cultured SVZ cells, but they do not direct these cells to a dopaminergic cell fate (Deleidi et al., 2011). These protocols can generate dopaminergic neurons, however, if the SVZ progenitors are first converted into pluripotent stem cells by Oct4 over-expression (Deleidi et al., 2011). Oct4 has a central role in stem cell pluripotency and differentiation, and is sufficient to reprogram adult neural stem cells into pluripotent stem cells (Pesce and Scholer, 2001; Kim et al., 2009). About 5\% of the total cells in culture can be directed to adopt a midbrain dopaminergic neuronal phenotype when SVZ progenitors are reprogrammed by Oct4 over-expression. Transplantation of cultures with these reprogrammed dopaminergic neurons into 6-hydroxydopamine lesioned rats produced significant and reproducible functional improvement for up to 2 months after the procedure (Deleidi et al., 2011).

An alternative genetic engineering strategy for improving dopaminergic neuron yields is to over-express transcription factors that specify cell fate during normal development. This approach has been successfully used with both embryonic and induced pluripotent stem cells (Chung et al., 2002, 2005; Kim et al., 2002; Andersson et al., 2006; Martinat et al., 2006; Friling et al., 2009; Sanchez-Danes et al., 2012; Theka et al., 2013). Both Mash-1 and Nurr1 genes encode transcription factors that are involved in the specification of midbrain dopaminergic neurons (Park et al., 2006). Retroviral-mediated over-expression of these transcription factors can direct a substantial percentage $(\sim 37 \%)$ of the total number of cultured adult SVZ cells to express dopaminergic neuronal markers (Shim et al., 2007). Transplantation of these cells in 6-hydroxydopamine lesioned rats also produces robust functional improvement.

\section{SVZ/OLFACTORY BULB DOPAMINERGIC PHENOTYPE AS A POTENTIAL REPLACEMENT CELL SOURCE}

Adult SVZ neural stem cells normally generate dopaminergic interneurons and both Mash1 and Nurr1-family transcription factors are important for specification of these interneurons (Cave and Baker, 2009). Although the over-expression of Mash1 and 
Nurrl was intended to generate dopaminergic neurons with a midbrain phenotype, this strategy may have generated either A16 olfactory bulb dopaminergic neurons or hybrid A16 neurons. The ability of the dopaminergic neurons generated by Shim and coworkers to significantly improve functional performance in the rodent $\mathrm{PD}$ model, raises the possibility that either an A16 or a hybrid A16 dopaminergic neuron is a viable alternative for cell replacement strategies.

Non-midbrain dopaminergic neurons are not typically considered for replacement cells in PD. This is due, in part, to studies of transplanted dopaminergic neurons from non-mesencepahlic brain regions. Grafts of diencephalic dopaminergic neurons from either rodent or human embryonic hypothalamic tissue poorly integrated into the host striatum and provided no significant functional benefit in PD models (Abrous et al., 1988; Zuddas et al., 1991; Frodl et al., 1994). Furthermore, previous clinical trials grafting tissue containing catecholaminergic neurons from non-brain regions, including the adrenal medulla, carotid body, retinal epithelium and sympathetic ganglion neurons, demonstrated either only marginal or no significant benefit. In addition, morbidities associated some procedures, such as autografts of either adrenal medulla and sympathetic ganglia, have further discouraged exploration of non-midbrain phenotypes as replacement cells (reviewed in Wijeyekoon and Barker, 2009).

Olfactory bulb dopaminergic neurons have several favorable attributes, however, that are distinct from these previously tested non-midbrain phenotypes. Like other adult-generated neurons, olfactory bulb dopaminergic progenitors can integrate into pre-existing neural circuitry. Mature neurons are likely able to innervate large areas of striatum since they have processes that typically extend for over $200 \mu \mathrm{m}$ and, in some cases, over $700 \mu \mathrm{m}$ (Kiyokage et al., 2010). Like their counterparts in the substantia nigra, a prominent electrophysiological property of olfactory bulb dopaminergic neurons is a capacity to generate auto-rhythmic action potentials (Pignatelli et al., 2005; Guzman et al., 2009). Unlike the substantia nigra, however, olfactory bulb dopaminergic neurons are not vulnerable in PDmediated neurodegeneration (Huisman et al., 2004). Consistent with this reduced vulnerability, olfactory bulb dopaminergic neurons lack $\alpha$-synuclein deposits in rodents over-expressing this protein (Ubeda-Banon et al., 2010). Several PD patients surviving at least 10 years after intrastriatal grafts of fetal mesencephalic tissue have shown accumulation of $\alpha$-synuclein in grafted neurons (Kordower et al., 2008a,b; Li et al., 2008, 2010; Mendez et al., 2008). Whether this accumulation adversely affects the function or survival of replacement neurons is not known, but it does suggest that replacement neurons of the midbrain phenotype are susceptible to PD in the long-term. Replacement neurons with the olfactory bulb dopaminergic phenotype, however, are expected to be less vulnerable to this pathology.

\section{CHALLENGES FOR DEVELOPING ADULT SVZ CELLS AS REPLACEMENT CELLS}

Developing adult SVZ cells into a clinically suitable autologous source of replacement neurons faces several challenges. One challenge is to enhance survival rates of engrafted cells. Studies with embryonic and induced pluripotent stem cells, for which long-term survival is also an issue, have indicated that treating the donor cells with antioxidants or growth factors can increase survival rates (Nakao et al., 1994; Apostolides et al., 1998; Espejo et al., 2000; Hoglinger et al., 2001; Andereggen et al., 2009). The presence of neurotransmitters in the culture conditions may improve the ability to expand and differentiate cells with neuronal phenotypes since neurotransmitters can modulate proliferation, migration and survival of SVZ-derived cells in the endogenous SVZ neurogenic niche (reviewed in Young et al., 2011). In addition, pre-conditioning recipients by administering growth factors may also be an important strategy to improve long-term survival (Chen et al., 2007a). Elucidating culture conditions that promote neuronal progenitor expansion and survival will be critical for developing standardized preparations to generate clinically suitable replacement cells from adult SVZ neural stem cells.

A second challenge is the suppression of glial progenitor proliferation and survival. SVZ neural stem cells prodigiously generate neuronal progenitors in their endogenous niche, but most of the progenitors generated by these cells either do not to survive or they adopt alternative fates when cultured in vitro and transplanted into the striatum. Furthermore, proportional levels of glial production increase with either the age of the SVZ neural stem cell donor or the length of time that the stem cells are cultured (Gritti et al., 2009). Since most PD patients are advanced in age, the propensity of autologously derived SVZ stem cells to produce glia is an important challenge to address. Protocols for in vitro expansion of SVZ progenitors typically use growth factor combinations that include epidermal growth factor (EGF) (Deleyrolle and Reynolds, 2009). The inclusion of this growth factor, however, may be detrimental for neuronal progenitor production since stimulation of EGF receptors promotes glial progenitor proliferation and differentiation in the SVZ (Aguirre and Gallo, 2007; Gonzalez-Perez and Quinones-Hinojosa, 2010; Gonzalez-Perez and Alvarez-Buylla, 2011). Alternatively, culture media may require other growth factors to suppress glial differentiation. Expansion of neurospheres derived from the adult SVZ in media containing both EGF and FGF9 enhances neuronal proliferation while diminishing both oligodendrocyte and astrocyte progenitor production (Lum et al., 2009). Supplementing in vitro culture conditions with Noggin may also enhance suppression of glial phenotypes. SVZ neural stem cells and neural progenitors express BMP receptors and antagonism of these receptors by Noggin inhibits glial differentiation (Lim et al., 2000). Furthermore, cell-sorting techniques can facilitate the removal of glial progenitors from SVZ-derived cultures prior to transplantation. Recent studies with human pluripotent progenitors showed that glial progenitors can be successfully isolated from mixed cultures based on co-expression of CD44 and CD184 (Yuan et al., 2011).

A third challenge is developing efficient methods to produce dopaminergic neurons. Treatment either with growth factors, morphogens, signaling molecules, or chromatin modifying agents does not direct SVZ-derived progenitors toward a dopaminergic fate. By contrast, significant dopaminergic neuron production has been only achieved through genetic modification of SVZ-derived progenitors (Shim et al., 2007; Deleidi et al., 2011). These genetic engineering methods, however, come with 
some caveats. Reprogramming of SVZ neural stem cells into pluripotent cells prior to dopaminergic differentiation introduces the same safety concerns associated with induced pluripotent stem cell strategies. Retroviral transduction of SVZ progenitors to over-express transcription factor genes, such as Nurr1 and Mash1, avoids the concerns of genetic reprogramming, but retroviruses are questionable for clinical application since they can increase the risk of tumor formation by disrupting endogenous gene expression upon their insertion into the host genome (Yi et al., 2011). Genetically engineering SVZ progenitors for cell replacement therapy in PD will likely require one of the other available methods to transduce cells (Lowry and Plath, 2008).

Even though over-expression of Nurr1 and Mash1 has provided the best yield of SVZ-derived dopaminergic neurons to date, only a subset of transduced cells adopted a dopaminergic phenotype. This partial induction may reflect the heterogeneity within the SVZ stem cell niche. Specific subsets of olfactory bulb interneurons are generated from the neural stem cells that are spatially localized in distinct regions of the adult SVZ (Kelsch et al., 2007; Merkle et al., 2007; Young et al., 2007; Brill et al., 2009). Further studies are required to establish whether adult SVZ neural stem cells from spatially distinct regions are limited in their capacity to generate dopaminergic progenitors in vitro. In addition to transcription factors, heterogeneous expression of microRNAs may also be instrumental in shaping the in vitro potential of adult SVZ neural stem cells to generate dopaminergic neurons (De Chevigny et al., 2012). Further studies are also required to address whether the dopaminergic neurons produced with SVZ-derived progenitors either adopt an olfactory bulb, midbrain or a hybrid dopaminergic phenotype. As discussed above, the olfactory bulb phenotype may be clinically advantageous for replacement cells, but one concern is that olfactory bulb dopaminergic interneurons also co-express of GABA (Kiyokage et al., 2010). The effect of GABA in these potential replacement cells is difficult to predict, but recent studies suggest that nigral dopaminergic neurons inhibit striatal output through the co-release of both dopamine and GABA (Tritsch et al., 2012). Consistent with this observation, about $10 \%$ of dopaminergic neurons in substantia nigra pars compacta are reported to co-express mRNA for the GABA biosynthetic enzyme glutamate decarboxylase 65 (Gonzalez-Hernandez et al., 2001). Thus, the co-expressed GABAergic phenotype in olfactory bulb dopaminergic interneurons may be more of a similarity than a difference with nigral dopaminergic neurons. Studies in rodent $\mathrm{PD}$ animal models are needed, however, to demonstrate whether the olfactory bulb or a hybrid dopaminergic phenotype can provide functional recovery without producing deleterious side effects.

\section{CONCLUSIONS}

The adult SVZ is a promising source of neural stem cells to generate dopaminergic neuronal progenitors for cell transplant strategies in PD. Since these stem cells can be endogenously harvested from patients, they are a potential autologous source of replacement cells. As discussed in this review, however, there are several important technical issues to be addressed in order for adult SVZ neural stem cells to be competitive source for clinically suitable dopaminergic neurons.

\section{REFERENCES}

Abrous, N., Guy, J., Vigny, A., Calas, A., Le Moal, M., and Herman, J. P. (1988). Development of intracerebral dopaminergic grafts: a combined immunohistochemical and autoradiographic study of its time course and environmental influences. J. Comp. Neurol. 273, 26-41. doi: 10.1002/cne.902730104

Aguirre, A., and Gallo, V. (2007). Reduced EGFR signaling in progenitor cells of the adult subventricular zone attenuates oligodendrogenesis after demyelination. Neuron Glia Biol. 3, 209-220. doi: 10.1017/S1740925X08000082

Andereggen, L., Meyer, M., Guzman, R., Ducray, A. D., and Widmer, H. R. (2009). Effects of GDNF pretreatment on function and survival of transplanted fetal ventral mesencephalic cells in the 6-OHDA rat model of Parkinson's disease. Brain Res. 1276, 39-49. doi: 10.1016/j.brainres.2009.04.021

Andersson, E., Tryggvason, U., Deng, Q., Friling, S., Alekseenko, Z., Robert, B., et al. (2006). Identification of intrinsic determinants of midbrain dopamine neurons. Cell 124, 393-405. doi: 10.1016/j.cell.2005.10.037

Apostolides, C., Sanford, E., Hong, M., and Mendez, I. (1998). Glial cell line-derived neurotrophic factor improves intrastriatal graft survival of stored dopaminergic cells. Neuroscience 83, 363-372. doi: 10.1016/S03064522(97)00369-2

Bjorklund, L. M., Sanchez-Pernaute, R., Chung, S., Andersson, T., Chen, I. Y., Mcnaught, K. S., et al. (2002). Embryonic stem cells develop into functional dopaminergic neurons after transplantation in a Parkinson rat model. Proc. Natl. Acad. Sci. U.S.A. 99, 2344-2349. doi: 10.1073/pnas.022438099

Boyer, L. F., Campbell, B., Larkin, S., Mu, Y., and Gage, F. H. (2012). Dopaminergic differentiation of human pluripotent cells. Curr. Protoc. Stem Cell Biol. Chapter 1:Unit1H.6. doi: 10.1002/9780470151808.sc01h06s22

Braak, H., Ghebremedhin, E., Rub, U., Bratzke, H., and Del Tredici, K. (2004). Stages in the development of Parkinson's disease-related pathology. Cell Tissue Res. 318, 121-134. doi: 10.1007/s00441-004-0956-9

Brill, M. S., Ninkovic, J., Winpenny, E., Hodge, R. D., Ozen, I., Yang, R., et al. (2009). Adult generation of glutamatergic olfactory bulb interneurons. Nat. Neurosci. 12, 1524-1533. doi: 10.1038/nn.2416

Carlsson, T., Carta, M., Winkler, C., Bjorklund, A., and Kirik, D. (2007). Serotonin neuron transplants exacerbate L-DOPA-induced dyskinesias in a rat model of Parkinson's disease. J. Neurosci. 27, 8011-8022. doi: 10.1523/JNEUROSCI.207907.2007

Carlsson, T., Winkler, C., Lundblad, M., Cenci, M. A., Bjorklund, A., and Kirik, D. (2006). Graft placement and uneven pattern of reinnervation in the striatum is important for development of graft-induced dyskinesia. Neurobiol. Dis. 21, 657-668. doi: 10.1016/j.nbd.2005.09.008

Cave, J. W., and Baker, H. (2009). Dopamine systems in the forebrain. Adv. Exp. Med. Biol. 651, 15-35. doi: 10.1007/978-1-4419-0322-8_2

Chang, Y. L., Chen, S. J., Kao, C. L., Hung, S. C., Ding, D. C., Yu, C. C., et al. (2012). Docosahexaenoic acid promotes dopaminergic differentiation in induced pluripotent stem cells and inhibits teratoma formation in rats with Parkinsonlike pathology. Cell Transplant. 21, 313-332. doi: 10.3727/096368911X580572

Chen, K., Henry, R. A., Hughes, S. M., and Connor, B. (2007a). Creating a neurogenic environment: the role of BDNF and FGF2. Mol. Cell. Neurosci. 36, 108-120. doi: 10.1016/j.mcn.2007.06.004

Chen, K., Hughes, S. M., and Connor, B. (2007b). Neural progenitor cells derived from the adult rat subventricular zone: characterization and transplantation. Cell Transplant. 16, 799-810. doi: 10.3727/000000007783465253

Cho, M. S., Lee, Y. E., Kim, J. Y., Chung, S., Cho, Y. H., Kim, D. S., et al. (2008). Highly efficient and large-scale generation of functional dopamine neurons from human embryonic stem cells. Proc. Natl. Acad. Sci. U.S.A. 105, 3392-3397. doi: 10.1073/pnas.0712359105

Chung, S., Hedlund, E., Hwang, M., Kim, D. W., Shin, B. S., Hwang, D. Y., et al. (2005). The homeodomain transcription factor Pitx3 facilitates differentiation of mouse embryonic stem cells into AHD2-expressing dopaminergic neurons. Mol. Cell. Neurosci. 28, 241-252. doi: 10.1016/j.mcn.2004.09.008

Chung, S., Sonntag, K. C., Andersson, T., Bjorklund, L. M., Park, J. J., Kim, D. W., et al. (2002). Genetic engineering of mouse embryonic stem cells by Nurrl enhances differentiation and maturation into dopaminergic neurons. Eur. J. Neurosci. 16, 1829-1838. doi: 10.1046/j.1460-9568.2002.02255.x

De Chevigny, A., Core, N., Follert, P., Gaudin, M., Barbry, P., Beclin, C., et al. (2012). miR-7a regulation of Pax6 controls spatial origin of forebrain dopaminergic neurons. Nat. Neurosci. 15, 1120-1126. doi: 10.1038/nn.3142

Defer, G. L., Geny, C., Ricolfi, F., Fenelon, G., Monfort, J. C., Remy, P., et al. (1996). Long-term outcome of unilaterally transplanted parkinsonian patients. I. Clinical approach. Brain 119(Pt 1), 41-50. doi: 10.1093/brain/119.1.41 
Deleidi, M., Cooper, O., Hargus, G., Levy, A., and Isacson, O. (2011). Oct4-induced reprogramming is required for adult brain neural stem cell differentiation into midbrain dopaminergic neurons. PLoS ONE 6:e19926. doi: 10.1371/journal.pone.0019926

Deleyrolle, L. P., and Reynolds, B. A. (2009). Isolation, expansion, and differentiation of adult Mammalian neural stem and progenitor cells using the neurosphere assay. Methods Mol. Biol. 549, 91-101. doi: 10.1007/978-1-60327931-4_7

Espejo, M., Cutillas, B., Arenas, T. E., and Ambrosio, S. (2000). Increased survival of dopaminergic neurons in striatal grafts of fetal ventral mesencephalic cells exposed to neurotrophin-3 or glial cell line-derived neurotrophic factor. Cell Transplant. 9, 45-53.

Freed, C. R., Greene, P. E., Breeze, R. E., Tsai, W. Y., Dumouchel, W., Kao, R., et al. (2001). Transplantation of embryonic dopamine neurons for severe Parkinson's disease. N. Engl. J. Med. 344, 710-719. doi: 10.1056/NEJM200103083 441002

Friling, S., Andersson, E., Thompson, L. H., Jonsson, M. E., Hebsgaard, J. B., Nanou, E., et al. (2009). Efficient production of mesencephalic dopamine neurons by Lmxla expression in embryonic stem cells. Proc. Natl. Acad. Sci. U.S.A. 106, 7613-7618. doi: 10.1073/pnas.0902396106

Frodl, E. M., Duan, W. M., Sauer, H., Kupsch, A., and Brundin, P. (1994). Human embryonic dopamine neurons xenografted to the rat: effects of cryopreservation and varying regional source of donor cells on transplant survival, morphology and function. Brain Res. 647, 286-298. doi: 10.1016/0006-8993(94)91328-5

Gage, F. H., Kempermann, G., and Song, H. (2008). Adult Neurogenesis. Cold Spring Harbor, NY: Cold Spring Harbor Laboratory Press.

Gonzalez-Hernandez, T., Barroso-Chinea, P., Acevedo, A., Salido, E., and Rodriguez, M. (2001). Colocalization of tyrosine hydroxylase and GAD65 mRNA in mesostriatal neurons. Eur. J. Neurosci. 13, 57-67. doi: 10.1111/j.14609568.2001.01371.x

Gonzalez-Perez, O., and Alvarez-Buylla, A. (2011). Oligodendrogenesis in the subventricular zone and the role of epidermal growth factor. Brain Res. Rev. 67, 147-156. doi: 10.1016/j.brainresrev.2011.01.001

Gonzalez-Perez, O., and Quinones-Hinojosa, A. (2010). Dose-dependent effect of EGF on migration and differentiation of adult subventricular zone astrocytes. Glia 58, 975-983. doi: 10.1002/glia.20979

Gritti, A., Dal Molin, M., Foroni, C., and Bonfanti, L. (2009). Effects of developmental age, brain region, and time in culture on long-term proliferation and multipotency of neural stem cell populations. J. Comp. Neurol. 517, 333-349. doi: $10.1002 / \mathrm{cne} .22153$

Guzman, J. N., Sanchez-Padilla, J., Chan, C. S., and Surmeier, D. J. (2009). Robust pacemaking in substantia nigra dopaminergic neurons. J. Neurosci. 29, 11011-11019. doi: 10.1523/JNEUROSCI.2519-09.2009.

Hagell, P., and Brundin, P. (2001). Cell survival and clinical outcome following intrastriatal transplantation in Parkinson disease. J. Neuropathol. Exp. Neurol. 60, 741-752.

Hargus, G., Cooper, O., Deleidi, M., Levy, A., Lee, K., Marlow, E., et al. (2010). Differentiated Parkinson patient-derived induced pluripotent stem cells grow in the adult rodent brain and reduce motor asymmetry in Parkinsonian rats. Proc. Natl. Acad. Sci. U.S.A. 107, 15921-15926. doi: 10.1073/pnas.1010209107

Herrera, D. G., Garcia-Verdugo, J. M., and Alvarez-Buylla, A. (1999). Adultderived neural precursors transplanted into multiple regions in the adult brain. Ann. Neurol. 46, 867-877. doi: 10.1002/1531-8249(199912)46:6\%3C867::AIDANA9\%3E3.0.CO;2-Z

Hoglinger, G. U., Widmer, H. R., Spenger, C., Meyer, M., Seiler, R. W., Oertel, W. H., et al. (2001). Influence of time in culture and BDNF pretreatment on survival and function of grafted embryonic rat ventral mesencephalon in the 6-OHDA rat model of Parkinson's disease. Exp. Neurol. 167, 148-157. doi: 10.1006/exnr.2000.7546

Huisman, E., Uylings, H. B., and Hoogland, P. V. (2004). A 100\% increase of dopaminergic cells in the olfactory bulb may explain hyposmia in Parkinson's disease. Mov. Disord. 19, 687-692. doi: 10.1002/mds.10713

Ihrie, R. A., and Alvarez-Buylla, A. (2011). Lake-front property: a unique germinal niche by the lateral ventricles of the adult brain. Neuron 70, 674-686. doi: 10.1016/j.neuron.2011.05.004

Kelsch, W., Mosley, C. P., Lin, C. W., and Lois, C. (2007). Distinct mammalian precursors are committed to generate neurons with defined dendritic projection patterns. PLoS Biol. 5:e300. doi: 10.1371/journal.pbio.0050300
Kim, J. B., Sebastiano, V., Wu, G., Arauzo-Bravo, M. J., Sasse, P., Gentile, L., et al. (2009). Oct4-induced pluripotency in adult neural stem cells. Cell 136, 411-419. doi: 10.1016/j.cell.2009.01.023

Kim, J. H., Auerbach, J. M., Rodriguez-Gomez, J. A., Velasco, I., Gavin, D., Lumelsky, N., et al. (2002). Dopamine neurons derived from embryonic stem cells function in an animal model of Parkinson's disease. Nature 418, 50-56. doi: $10.1038 /$ nature 00900

Kiyokage, E., Pan, Y. Z., Shao, Z., Kobayashi, K., Szabo, G., Yanagawa, Y., et al. (2010). Molecular identity of periglomerular and short axon cells. J. Neurosci. 30, 1185-1196. doi: 10.1523/JNEUROSCI.3497-09.2010

Kordower, J. H., Chu, Y., Hauser, R. A., Freeman, T. B., and Olanow, C. W. (2008a). Lewy body-like pathology in long-term embryonic nigral transplants in Parkinson's disease. Nat. Med. 14, 504-506. doi: 10.1038/nm1747

Kordower, J. H., Chu, Y., Hauser, R. A., Olanow, C. W., and Freeman, T. B. (2008b). Transplanted dopaminergic neurons develop PD pathologic changes: a second case report. Mov. Disord. 23, 2303-2306. doi: 10.1002/mds.22369

Kriks, S., and Studer, L. (2009). Protocols for generating ES cell-derived dopamine neurons. Adv. Exp. Med. Biol. 651, 101-111. doi: 10.1007/978-1-4419-0322-8_10

Li, J. Y., Englund, E., Holton, J. L., Soulet, D., Hagell, P., Lees, A. J., et al. (2008). Lewy bodies in grafted neurons in subjects with Parkinson's disease suggest host-to-graft disease propagation. Nat. Med. 14, 501-503. doi: 10.1038/nm1746

Li, J. Y., Englund, E., Widner, H., Rehncrona, S., Bjorklund, A., Lindvall, O., et al. (2010). Characterization of Lewy body pathology in 12- and 16-year-old intrastriatal mesencephalic grafts surviving in a patient with Parkinson's disease. Mov. Disord. 25, 1091-1096. doi: 10.1002/mds.23012

Lim, D. A., Tramontin, A. D., Trevejo, J. M., Herrera, D. G., Garcia-Verdugo, J. M., and Alvarez-Buylla, A. (2000). Noggin antagonizes BMP signaling to create a niche for adult neurogenesis. Neuron 28, 713-726. doi: 10.1016/S08966273(00)00148-3

Lindvall, O., and Bjorklund, A. (2011). Cell therapeutics in Parkinson's disease. Neurotherapeutics 8, 539-548. doi: 10.1007/s13311-011-0069-6

Lois, C., and Alvarez-Buylla, A. (1994). Long-distance neuronal migration in the adult mammalian brain. Science 264, 1145-1148. doi: 10.1126/science.8178174

Lowry, W. E., and Plath, K. (2008). The many ways to make an iPS cell. Nat. Biotechnol. 26, 1246-1248. doi: 10.1038/nbt1108-1246

Lum, M., Turbic, A., Mitrovic, B., and Turnley, A. M. (2009). Fibroblast growth factor-9 inhibits astrocyte differentiation of adult mouse neural progenitor cells. J. Neurosci. Res. 87, 2201-2210. doi: 10.1002/jnr.22047

Luskin, M. B. (1993). Restricted proliferation and migration of postnatally generated neurons derived from the forebrain subventricular zone. Neuron 11, 173-189. doi: 10.1016/0896-6273(93)90281-U

Ma, Y., Feigin, A., Dhawan, V., Fukuda, M., Shi, Q., Greene, P., et al. (2002). Dyskinesia after fetal cell transplantation for parkinsonism: a PET study. Ann. Neurol. 52, 628-634. doi: 10.1002/ana.10359

Maries, E., Kordower, J. H., Chu, Y., Collier, T. J., Sortwell, C. E., Olaru, E., et al. (2006). Focal not widespread grafts induce novel dyskinetic behavior in parkinsonian rats. Neurobiol. Dis. 21, 165-180. doi: 10.1016/j.nbd.2005.07.002

Martinat, C., Bacci, J. J., Leete, T., Kim, J., Vanti, W. B., Newman, A. H., et al. (2006). Cooperative transcription activation by Nurr1 and Pitx 3 induces embryonic stem cell maturation to the midbrain dopamine neuron phenotype. Proc. Natl. Acad. Sci. U.S.A. 103, 2874-2879. doi: 10.1073/pnas.0511153103

Meissner, K. K., Kirkham, D. L., and Doering, L. C. (2005). Transplants of neurosphere cell suspensions from aged mice are functional in the mouse model of Parkinson's. Brain Res. 1057, 105-112. doi: 10.1016/j.brainres.2005.07.057

Mendez, I., Dagher, A., Hong, M., Gaudet, P., Weerasinghe, S., Mcalister, V., et al. (2002). Simultaneous intrastriatal and intranigral fetal dopaminergic grafts in patients with Parkinson disease: a pilot study. Report of three cases. J. Neurosurg. 96, 589-596. doi: 10.3171/jns.2002.96.3.0589

Mendez, I., Vinuela, A., Astradsson, A., Mukhida, K., Hallett, P., Robertson, H., et al. (2008). Dopamine neurons implanted into people with Parkinson's disease survive without pathology for 14 years. Nat. Med. 14, 507-509. doi: $10.1038 / \mathrm{nm} 1752$

Merkle, F. T., Mirzadeh, Z., and Alvarez-Buylla, A. (2007). Mosaic organization of neural stem cells in the adult brain. Science 317, 381-384. doi: 10.1126/science. 1144914

Meyer, A. K., Maisel, M., Hermann, A., Stirl, K., and Storch, A. (2010). Restorative approaches in Parkinson's Disease: which cell type wins the race? J. Neurol. Sci. 289, 93-103. doi: 10.1016/j.jns.2009.08.024 
Nakao, N., Frodl, E. M., Duan, W. M., Widner, H., and Brundin, P. (1994). Lazaroids improve the survival of grafted rat embryonic dopamine neurons. Proc. Natl. Acad. Sci. U.S.A. 91, 12408-12412. doi: 10.1073/pnas.91.26.12408

Nussbaum, R. L., and Ellis, C. E. (2003). Alzheimer's disease and Parkinson's disease. N. Engl. J. Med. 348, 1356-1364. doi: 10.1056/NEJM2003ra020003

Olanow, C. W., Goetz, C. G., Kordower, J. H., Stoessl, A. J., Sossi, V., Brin, M. F., et al. (2003). A double-blind controlled trial of bilateral fetal nigral transplantation in Parkinson's disease. Ann. Neurol. 54, 403-414. doi: 10.1002/ana.10720

Park, C. H., Kang, J. S., Kim, J. S., Chung, S., Koh, J. Y., Yoon, E. H., et al. (2006). Differential actions of the proneural genes encoding Mash1 and neurogenins in Nurrl-induced dopamine neuron differentiation. J. Cell Sci. 119, 2310-2320. doi: $10.1242 /$ jcs. 02955

Pesce, M., and Scholer, H. R. (2001). Oct-4: gatekeeper in the beginnings of mammalian development. Stem Cells 19, 271-278. doi: 10.1634/stemcells.19-4-271

Pignatelli, A., Kobayashi, K., Okano, H., and Belluzzi, O. (2005). Functional properties of dopaminergic neurones in the mouse olfactory bulb. J. Physiol. 564 501-514. doi: 10.1113/jphysiol.2005.084632

Poewe, W. (2008). Non-motor symptoms in Parkinson's disease. Eur. J. Neurol. 15(Suppl. 1), 14-20. doi: 10.1111/j.1468-1331.2008.02056.x

Politis, M., Wu, K., Loane, C., Quinn, N. P., Brooks, D. J., Oertel, W. H., et al. (2012). Serotonin neuron loss and nonmotor symptoms continue in Parkinson's patients treated with dopamine grafts. Sci. Transl. Med. 4, 128ra141. doi: 10.1126/scitranslmed.3003391

Rhee, Y. H., Ko, J. Y., Chang, M. Y., Yi, S. H., Kim, D., Kim, C. H., et al. (2011). Protein-based human iPS cells efficiently generate functional dopamine neurons and can treat a rat model of Parkinson disease. J. Clin. Invest. 121, 2326-2335. doi: 10.1172/JCI45794

Richardson, R. M., Broaddus, W. C., Holloway, K. L., and Fillmore, H. L. (2005). Grafts of adult subependymal zone neuronal progenitor cells rescue hemiparkinsonian behavioral decline. Brain Res. 1032, 11-22. doi: 10.1016/j.brainres.2004.10.043

Rodriguez-Gomez, J. A., Lu, J. Q., Velasco, I., Rivera, S., Zoghbi, S. S., Liow, J. S., et al. (2007). Persistent dopamine functions of neurons derived from embryonic stem cells in a rodent model of Parkinson disease. Stem Cells 25, 918-928. doi: 10.1634/stemcells.2006-0386

Roy, N. S., Cleren, C., Singh, S. K., Yang, L., Beal, M. F., and Goldman, S. A. (2006). Functional engraftment of human ES cell-derived dopaminergic neurons enriched by coculture with telomerase-immortalized midbrain astrocytes. Nat. Med. 12, 1259-1268. doi: 10.1038/nm1495

Sanchez-Danes, A., Consiglio, A., Richaud, Y., Rodriguez-Piza, I., Dehay, B., Edel, M., et al. (2012). Efficient generation of A9 midbrain dopaminergic neurons by lentiviral delivery of LMX1A in human embryonic stem cells and induced pluripotent stem cells. Hum. Gene Ther. 23, 56-69. doi: 10.1089/hum.2011.054

Sanchez-Pernaute, R., Lee, H., Patterson, M., Reske-Nielsen, C., Yoshizaki, T., Sonntag, K. C., et al. (2008). Parthenogenetic dopamine neurons from primate embryonic stem cells restore function in experimental Parkinson's disease. Brain 131, 2127-2139. doi: 10.1093/brain/awn144

Seidenfaden, R., Desoeuvre, A., Bosio, A., Virard, I., and Cremer, H. (2006). Glial conversion of SVZ-derived committed neuronal precursors after ectopic grafting into the adult brain. Mol. Cell. Neurosci. 32, 187-198. doi: 10.1016/j.mcn.2006.04.003

Seki, T., Sawamoto, K., Parent, J. M., and Alvarez-Buylla, A. (2011). Neurogenesis in the Adult Brain I: Neurobiology. New York, NY: Springer.

Shim, J. W., Park, C. H., Bae, Y. C., Bae, J. Y., Chung, S., Chang, M. Y., et al. (2007). Generation of functional dopamine neurons from neural precursor cells isolated from the subventricular zone and white matter of the adult rat brain using Nurr1 overexpression. Stem Cells 25, 1252-1262. doi: 10.1634/stemcells.20060274

Sundberg, M., Bogetofte, H., Lawson, T., Jansson, J., Smith, G., Astradsson, A., et al. (2013). Improved cell therapy protocols for parkinson's disease based on differentiation efficiency and safety of hESC-, hiPSC-, and non-human primate iPSC-derived dopaminergic neurons. Stem Cells 31, 1548-1562. doi: 10.1002/stem.1415

Swistowski, A., Peng, J., Liu, Q., Mali, P., Rao, M. S., Cheng, L., et al. (2010). Efficient generation of functional dopaminergic neurons from human induced pluripotent stem cells under defined conditions. Stem Cells 28, 1893-1904. doi: 10.1002/stem.499

Takagi, Y., Takahashi, J., Saiki, H., Morizane, A., Hayashi, T., Kishi, Y., et al. (2005). Dopaminergic neurons generated from monkey embryonic stem cells function in a Parkinson primate model. J. Clin. Invest. 115, 102-109. doi: 10.1172/JCI21137

Theka, I., Caiazzo, M., Dvoretskova, E., Leo, D., Ungaro, F., Curreli, S., et al. (2013). Rapid generation of functional dopaminergic neurons from human induced pluripotent stem cells through a single-step procedure using cell lineage transcription factors. Stem Cells Transl. Med. 2, 473-479. doi: 10.5966/sctm.20120133

Tritsch, N. X., Ding, J. B., and Sabatini, B. L. (2012). Dopaminergic neurons inhibit striatal output through non-canonical release of GABA. Nature 490, 262-266. doi: 10.1038/nature11466

Ubeda-Banon, I., Saiz-Sanchez, D., De La Rosa-Prieto, C., Mohedano-Moriano, A., Fradejas, N., Calvo, S., et al. (2010). Staging of alpha-synuclein in the olfactory bulb in a model of Parkinson's disease: cell types involved. Mov. Disord. 25, 1701-1707. doi: 10.1002/mds.23197

Wernig, M., Zhao, J. P., Pruszak, J., Hedlund, E., Fu, D., Soldner, F., et al. (2008). Neurons derived from reprogrammed fibroblasts functionally integrate into the fetal brain and improve symptoms of rats with Parkinson's disease. Proc. Natl. Acad. Sci. U.S.A. 105, 5856-5861. doi: 10.1073/pnas.08016 77105

Westerlund, U., Svensson, M., Moe, M. C., Varghese, M., Gustavsson, B., Wallstedt, L., et al. (2005). Endoscopically harvested stem cells: a putative method in future autotransplantation. Neurosurgery 57, 779-784. discussion: 779-784. doi: 10.1227/01.NEU.0000176402.78462.cd

Widner, H., Tetrud, J., Rehncrona, S., Snow, B., Brundin, P., Gustavii, B., et al. (1992). Bilateral fetal mesencephalic grafting in two patients with parkinsonism induced by 1-methyl-4-phenyl-1,2,3,6-tetrahydropyridine (MPTP). N. Engl. J. Med. 327, 1556-1563. doi: 10.1056/NEJM199211263272203

Wijeyekoon, R., and Barker, R. A. (2009). Cell replacement therapy for Parkinson's disease. Biochim. Biophys. Acta 1792, 688-702. doi: 10.1016/j.bbadis.2008. 10.007

Yi, Y., Noh, M. J., and Lee, K. H. (2011). Current advances in retroviral gene therapy. Curr. Gene Ther. 11, 218-228. doi: 10.2174/156652311795684740

Young, K. M., Fogarty, M., Kessaris, N., and Richardson, W. D. (2007) Subventricular zone stem cells are heterogeneous with respect to their embryonic origins and neurogenic fates in the adult olfactory bulb. J. Neurosci. 27, 8286-8296. doi: 10.1523/JNEUROSCI.0476-07.2007

Young, S. Z., Taylor, M. M., and Bordey, A. (2011). Neurotransmitters couple brain activity to subventricular zone neurogenesis. Eur. J. Neurosci. 33, 1123-1132. doi: 10.1111/j.1460-9568.2011.07611.x

Yuan, S. H., Martin, J., Elia, J., Flippin, J., Paramban, R. I., Hefferan, M. P., et al. (2011). Cell-surface marker signatures for the isolation of neural stem cells, glia and neurons derived from human pluripotent stem cells. PLoS ONE 6:e17540. doi: 10.1371/journal.pone.0017540

Zhang, R. L., Zhang, L., Zhang, Z. G., Morris, D., Jiang, Q., Wang, L., et al. (2003). Migration and differentiation of adult rat subventricular zone progenitor cells transplanted into the adult rat striatum. Neuroscience 116, 373-382. doi: 10.1016/S0306-4522(02)00696-6

Zuddas, A., Corsini, G. U., Barker, J. L., Kopin, I. J., and Di Porzio, U. (1991). Specific Reinnervation of lesioned mouse striatum by grafted mesencephalic dopaminergic neurons. Eur. J. Neurosci. 3, 72-85. doi: 10.1111/j.14609568.1991.tb00813.x

Conflict of Interest Statement: The authors declare that the research was conducted in the absence of any commercial or financial relationships that could be construed as a potential conflict of interest.

Received: 29 November 2013; accepted: 22 January 2014; published online: 10 February 2014.

Citation: Cave JW, Wang $M$ and Baker H (2014) Adult subventricular zone neural stem cells as a potential source of dopaminergic replacement neurons. Front. Neurosci. 8:16. doi: 10.3389/fnins.2014.00016

This article was submitted to Neurogenesis, a section of the journal Frontiers in Neuroscience.

Copyright (c) 2014 Cave, Wang and Baker. This is an open-access article distributed under the terms of the Creative Commons Attribution License (CC BY). The use, distribution or reproduction in other forums is permitted, provided the original author(s) or licensor are credited and that the original publication in this journal is cited, in accordance with accepted academic practice. No use, distribution or reproduction is permitted which does not comply with these terms. 